\title{
AVALIAÇÃO DA RESTAURAÇÃO DAS ÁREAS DE PRESERVAÇÃO PERMANENTE DE PROPRIEDADES RURAIS, SITUADAS NO CÓRREGO DO GALANTE, EM MONTE CASTELO E TUPI PAULISTA, ESTADO DE SÃO PAULO
}

\author{
Jorge Watanabe', Antonio Lázaro Sant'Ana ${ }^{2}$
}

\begin{abstract}
${ }^{1}$ Mestre em Agronomia, FEIS/UNESP Ilha Solteira-Email: jorge.watanabe@cesp.com.br ${ }^{2}$ Prof. Doutor em Sociologia da FEIS/UNESP Ilha Solteira - Email: lazaro@agr.feis.unesp.br
\end{abstract}

RESUMO: Este artigo visa realizar uma análise da parceria constituída entre proprietários rurais da microbacia do córrego do Galante e a CESP - Companhia Energética de São Paulo para reconstituição da mata ciliar da Área de Preservação Permanente do referido Córrego por meio do Programa de Fomento Florestal. Esse Programa se constitui numa cooperação recíproca, na qual a CESP, após a análise da solicitação do interessado, fornece o projeto executivo, a orientação técnica para implantação e as mudas das espécies necessárias, enquanto o proprietário fornece a mão de obra e os insumos básicos requeridos para implantação do reflorestamento. Com base nos 52 projetos implantados pretendeu-se, por meio de visita às áreas e aplicação de questionários aos produtores, avaliar a qualidade técnica dos reflorestamentos e a percepção dos agricultores sobre o Projeto, de modo a identificar os fatores que contribuíram para o maior ou menor desenvolvimento das áreas reflorestadas. Identificou-se que as maiores dificuldades que os produtores encontraram na implantação da mata ciliar foram o controle das gramíneas, a irrigação das mudas, a construção de cercas e o controle das formigas. O ponto positivo mais citado pelos produtores foi que a restauração resultou na proteção das margens do córrego, enquanto o ponto negativo destacado foi o não pagamento pela recomposição que realizaram. A formalização destas parcerias interinstitucionais foi benéfica não só para o meio ambiente, mas também para os atores envolvidos, pois reduziu o custo e viabilizou a implantação da restauração das áreas de proteção pemanente - APPs para os produtores rurais, atendendo a exigência do Ministério Público Estadual; e permitiu à CESP continuar suas ações de recomposição de matas ciliares nas áreas impactadas pela formação dos lagos com um custo menor.

Palavras-chave: mata ciliar, reflorestamento, percepção dos produtores, parceria

\section{EVALUATION OF RESTORATION OF PERMANENT PRESERVATION AREA OF RURAL PROPERTY SITUATED IN GALANTE STREAM, IN MONTE CASTELO AND TUPI PAULISTA, SÃO PAULO STATE}

\begin{abstract}
This article aim to realize an analysis the partnership established between rural owners the Galante stream microbasin and CESP - Companhia Energética de São Paulo to rehabilitation of riparian forest with native species located in Permanent Preservation Area of above-mentioned stream thereby Promotion Forest Program. That Program consist in a reciprocal co-operation, where CESP, after the analysis of partner's request, provide the executive project, skill orientation to implementation and native seedling species necessaries, while,
\end{abstract}


the rural owner provide the manual work, the basic input needed to implementation of the reforestation. With date into fifty two projects established, we wished with visit in areas and questionnaire application into rural owners, to evaluate the technical quality of the reforestation, and the owner's perception about the project, and to identify the factors that contributed to higher or minor development of reforested areas. Were identified the major difficulties that the rural owner found in the riparian reforestation implementation like weed control, seedling irrigation, fence construction and ant control. The positive point most mentioned by owner were that the rehabilitation resulted in stream margin protection while negative point most mentioned were the no payment in the reconstitution realized. The formation of interinstitutional partnership were beneficial not only to environment, but to the actors involved too, because diminished the cost end implemented the APPs restoration to rural owners, answering the State Public Prosecutor request, and gave authorization to CESP continue yours actions of riparian forest restoration in a impacted area by the lakes formation with low cost.

Key words: riparian forest, reforestation, rural owner perception, partnership

\section{INTRODUÇÃO}

A construção de várias usinas hidrelétricas nos Rios Paraná e Tietê, no oeste do Estado de São Paulo, pela CESP Companhia Energética de São Paulo, ocasionou diversos impactos tanto do ponto de vista social, como do ecossistema natural, devido à formação das represas que desalojaram populações ribeirinhas e agricultores também afetou animais e a vegetação natural, como as matas ripárias.

A restauração de matas ciliares desenvolvida pela CESP visa à proteção dos solos e dos recursos hídricos nas áreas de drenagem dos reservatórios, a conservação e ampliação de espécies vegetais e animais e a manutenção da diversidade genética.

O programa de restauração é desenvolvido por meio de duas estratégias de atuação diferenciadas. Uma é o reflorestamento em áreas de propriedade da CESP, junto à borda do reservatório, compreendidas entre a cota normal de operação e a de desapropriação dos seus reservatórios e, fora da cota de desapropriação, via parceria com proprietários rurais localizados na área de influência do reservatório, por meio do Programa de Fomento Florestal (CESP, 1992).

O desenvolvimento do Programa de
Fomento Florestal, na microbacia do Córrego do Galante, teve início com a solicitação formalizada, em dezembro de 2006, pela Prefeitura Municipal de Monte Castelo, SP, a qual requereu apoio da CESP aos produtores rurais que haviam sido notificados pela Promotoria de Tupi Paulista a restaurar a vegetação ciliar de suas propriedades. Houve adesão de 52 proprietários rurais, cujas Áreas de Preservação Permanente a serem restauradas variaram de 0,18 a 16,07 hectares, totalizando 69,57 hectares, o que correspondeu ao plantio de 115.973 mudas.

Este trabalho de pesquisa teve como objetivo descrever e analisar os resultados da restauração de APPs, na microbacia do Córrego do Galante, assim como os possiveis beneficios $e$ as dificuldades de parcerias interinstitucionais relativas ao desenvolvimento do Programa de Fomento Florestal da CESP.

\section{MATERIAL E MÉTODOS}

O local de estudo foi a microbacia do córrego do Galante que abrange dois municípios da Região Alta Paulista. O córrego tem sua nascente em Tupi Paulista e deságua no Rio Aguapeí, nos limites do Parque Estadual do Aguapeí, município de Monte Castelo.

Foram pesquisadas 52 propriedades 
rurais dos municípios de Monte Castelo e Tupi Paulista, que representam o total de estabelecimentos que aderiam ao programa de Fomento Florestal da CESP (no total foram notificados 120 produtores pela Promotoria de Tupi Paulista).

A pesquisa realizada caracterizou-se pela combinação de uma abordagem quantitativa e qualitativa. Os instrumentos utilizados na coleta de dados consistiram em questionário sócio ambiental aplicado em 52 produtores rurais e observações diretas de campo. Estes instrumentos visaram, dentre outros aspectos, identificar possiveis mudanças da percepção dos produtores rurais com relação ao meio ambiente e às matas ciliares; avaliar a qualidade dos reflorestamentos utilizando-se de indicadores de monitoramento; e levantar os fatores que contribuiram para o maior ou menor desenvolvimento das áreas reflorestadas. Também foram analisadas as relações construídas pelas organizações sociais (produtores rurais, ministério público, técnicos de assistência rural, prefeitura municipais, CESP) na implantação da mata ciliar nas áreas de APPS.

A aplicação dos questionários junto aos produtores rurais foi realizada, em 2011, durante visitas às respectivas propriedades, nas quaís buscou-se empregar uma abordagem que proporcionasse aos entrevistados liberdade para expor os aspetos inerentes ao processo de implantação da mata ciliar, bem como a visão geral sobre projeto.

\section{Aspectos técnicos da restauração florestal realizada \\ De acordo com Kageyama et al.} (2003) a restauração florestal não deve ter como objetivo final refazer uma floresta exatamente como existia antes, mas sim de colocar no campo uma composição de espécies que tenha condições de se desenvolver e se autorenovar.

O projeto de restauração florestal previu a reconstituição da vegetação natural em consonância com a Resolução SMA n 8 , de 07 de março de 2007. Foram utilizadas espécies vegetais arbóreas pertencentes a estágios sucessionais distintos, manejadas com o propósito de favorecer o estabelecimento da dinâmica de sucessão natural. Nesta combinação, grupos de espécies com exigências complementares, principalmente quanto à necessidade de luz, são associados, de tal forma que as espécies de rápido crescimento ou pioneiras, sejam sombreadoras das espécies de crescimento lento (secundárias e clímax), proporcionando - rápido recobrimento da área, tutorando o crescimento e debilitando gramíneas invasoras.

Foram utilizadas 80 espécies na proporção de $50 \%$ pioneiras e $50 \%$ não pioneiras. Para a medição da largura da APP utilizou-se a base jurídica da lei $n^{\circ} 4.771 / 65$, portanto, a área de preservação permanente foi medida em faixa marginal a partir do limite externo do canal do Córrego e, onde tinha brejo, a partir do limite da área encharcada. Após o plantio das mudas, foram realizadas operações de manutenção que consistiram na realização de capinas, adubação de cobertura, combate às formigas e manutenção de aceiros. As etapas da implantação podem ser visualizadas na Figura 1.

Métodos de avaliação de reflorestamento

O método para atestar a qualidade da restauração das Áreas de Preservação Permanente foi o de utilizar indicadores de monitoramento, devido à facilidade de medição. Os indicadores de monitoramento foram baseados nos indicadores universais para monitoramento, contidos nos Cadernos da Mata ciliar, Monitoramento de áreas em recuperação $n^{\circ} 4$ (SMA, 2011), a saber:

\section{1-Cobertura do solo por espécies lenhosas.}

Avaliação visual das mudas mortas e avaliação do grau de matocompetição que influência na sobrevivência e desenvolvimento das mudas. 

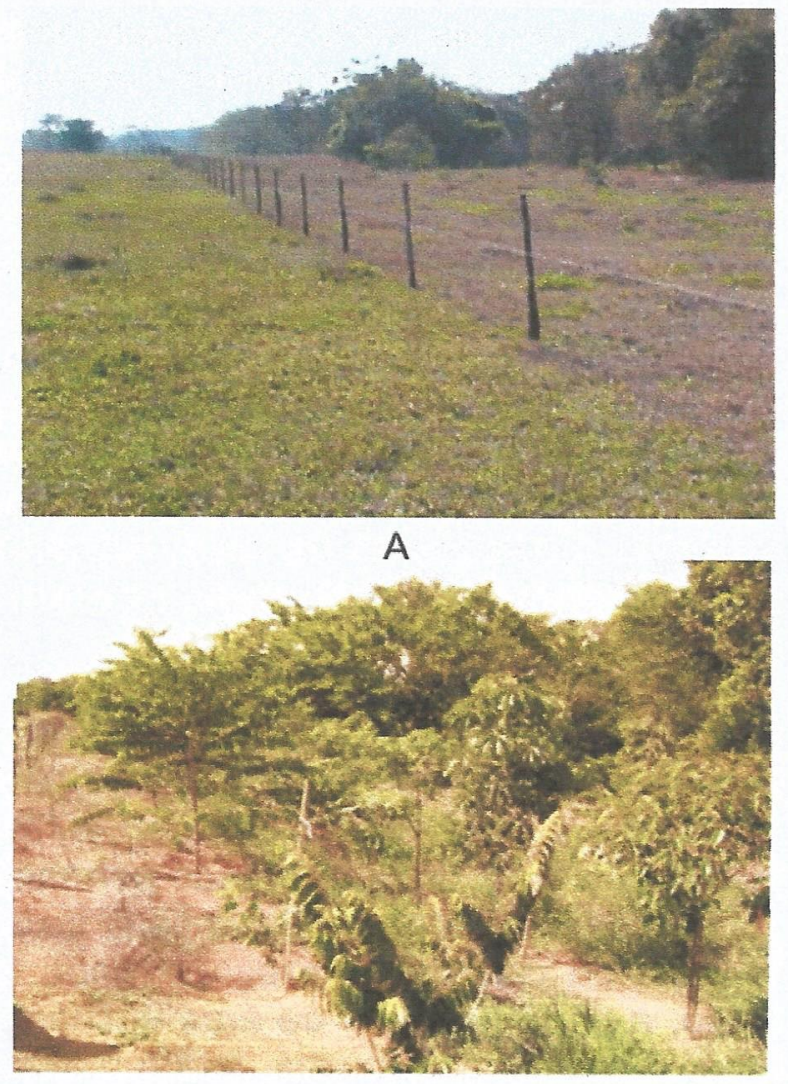

C

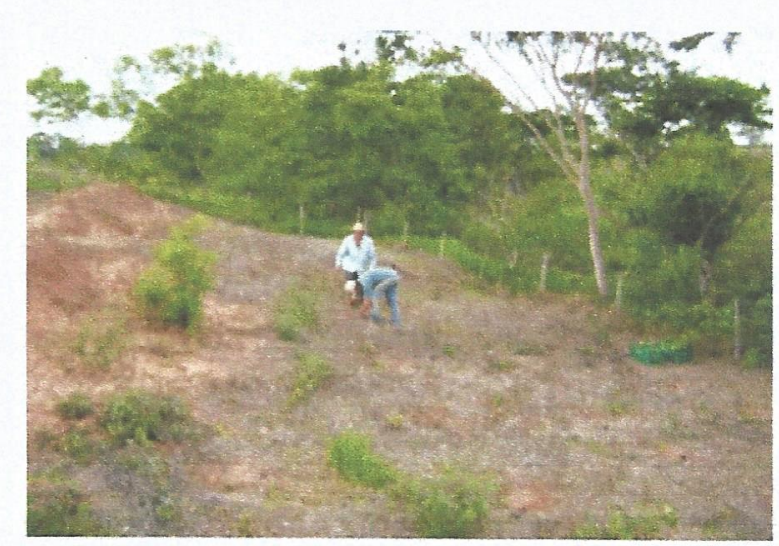

B

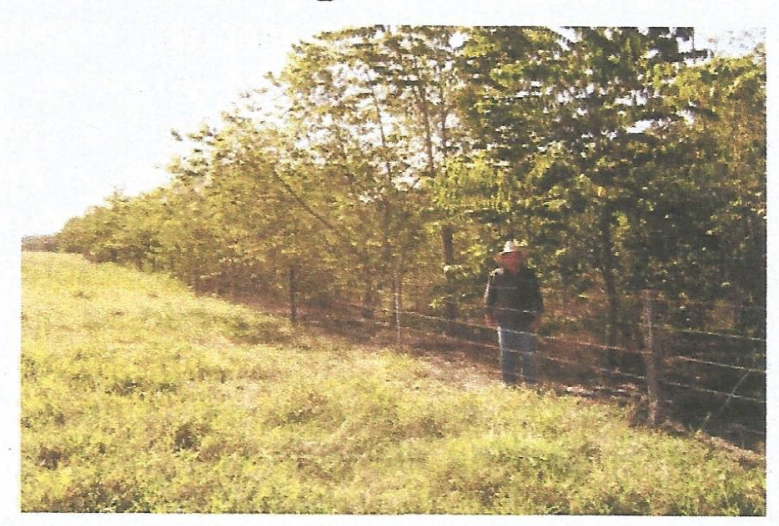

D

Figura 1. Etapas do reflorestamento ciliar implantado no sítio Santa Ana em Monte Castelo-SP: (A) Isolamento da área de APP (2007); (B) Plantio das mudas de espécies nativas (2007); (C) Desenvolvimento e manutenção de mudas plantadas (2009); (D) Mata ciliar implantada com 4 anos de idade (2011).

Fonte: Dados do próprio autor.

\section{2-Estratificação}

Espera-se encontrar de forma equilibrada, no estrato superior, as espécies pioneiras e no estrato inferior, as espécies tardias, que apresentam crescimento mais lento.

\section{3-Fisionomia florestal}

Verifica-se a restauração da fisionomia florestal, ou seja, uma mudança da fisionomia da área degradada para uma fisionomia de floresta, observando-se a reconstrução de dossel florestal.

Para verificação da conformidade da área restaurada, em comparação com a melhor área reflorestada, as áreas foram divididas em quatro categorias (Figura 2):

A - Plenamente restaurado: Não é necessário nenhum tipo de intervenção adicional e os tratos culturais não são mais necessários. A área pode ser considerada restaurada, o ecossistema atingiu o nível esperado de biodiversidade e funcionamento e o reflorestamento é autossustentável.

B - Quase totalmente restaurado: As mudas plantadas estão presentes na área, mas não estão com desenvolvimento adequado, devido a fatores que impedem o seu crescimento, como presença de gramíneas invasoras. É necessário continuar a manutenção da área eliminando as gramíneas.

C - Parcialmente restaurado: é necessária intervenção adicional, como eliminação dos fatores de degradação que, geralmente, são as gramineas invasoras e o replantio de mudas que não sobreviveram É preciso realizar enriquecimento ou adensamento da área.

D - Sem restauração: Devido à falta de manutenção ou outro problema durante a condução da área as mudas morreram e é necessário o plantio novamente em área total. 


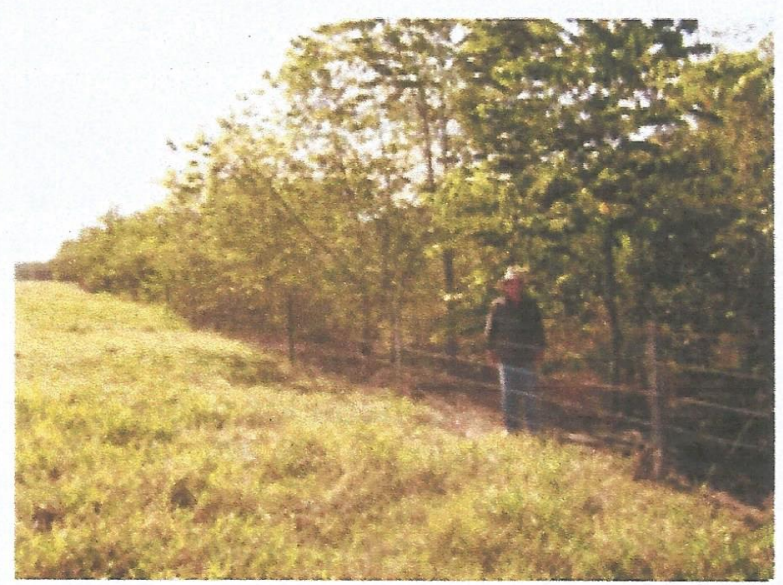

A

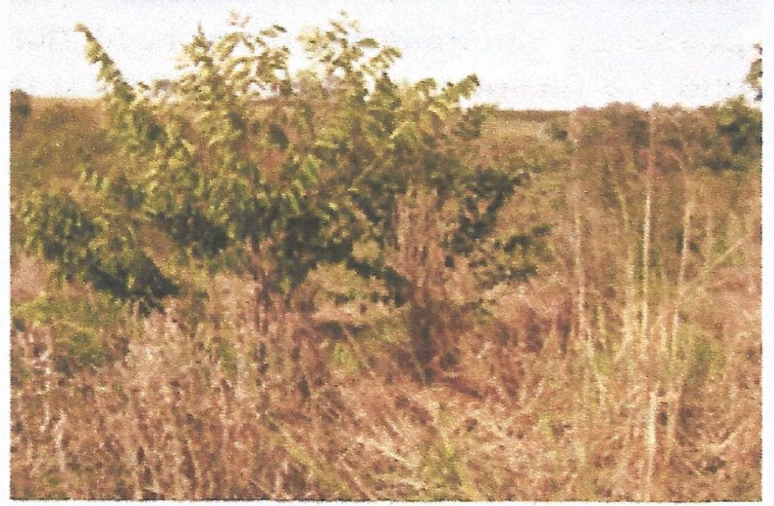

C

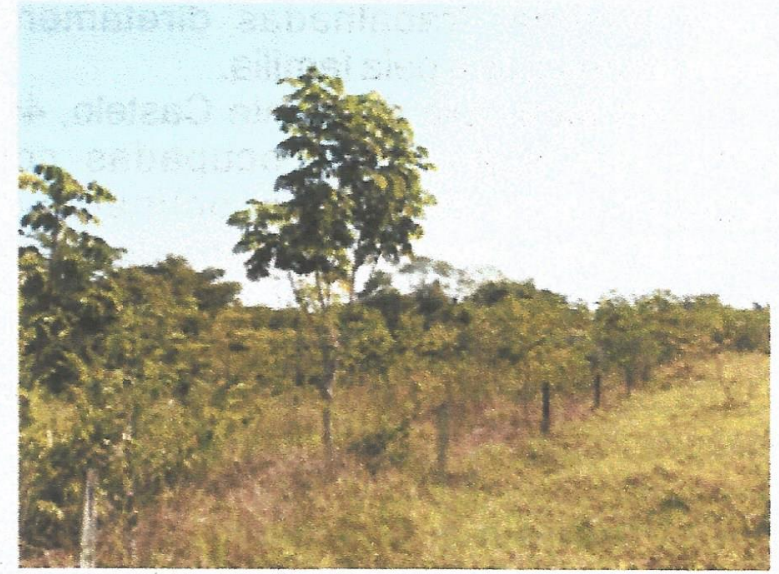

B

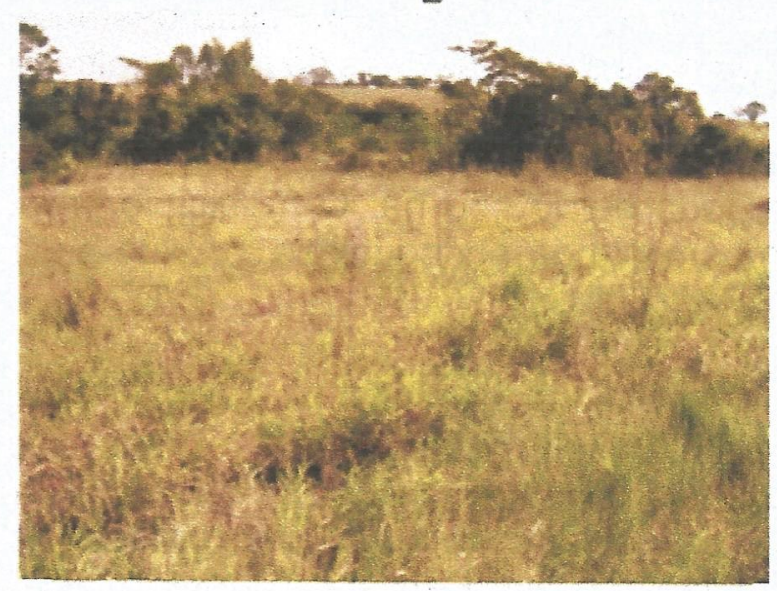

D

Figura 2. Projetos de reflorestamento ciliar através do Programa de Fomento Florestal no córrego do Galante, Monte Castelo (2011): (A) Plenamente restaurado; (B) Quase totalmente restaurado; (C) Parcialmente restaurado; (D) Sem restauração.

Fonte: Dados do próprio autor.

\section{RESULTADOS E DISCUSSÃO}

Caracterização da região de Monte Castelo e Tupi Paulista

Os municípios de Monte Castelo-SPe Tupi Paulista-SP são próximos e estão situados na zona da Alta Paulista, no espigão entre os rios do Peixe e Aguapeí.

O município de Monte Castelo área de $233,16(\mathrm{~km} 2)$, população de 4.060 pessoas e o seu índice de Desenvolvimento Humano IDH é de 0,743. O município de Tupi Paulista possui área de $244,65(\mathrm{~km} 2)$, população de 14.365 pessoas e o seu índice de Desenvolvimento Humano - IDH é de 0,792, um dos maiores do Estado de São Paulo (FUNDAÇÃO SEADE, 2009).

O levantamento Censitário de
Unidades de Produção Agropecuária (LUPA), realizado em 2007/08, sob coordenação da CATI (Coordenadoria de Assistência Técnica Integral), órgão vinculado à Secretária de Agricultura e Abastecimento do Governo do Estado de São Paulo, aponta um total de 466 Unidades de Produção Agropecuária (UPA's) no município de Monte Castelo, distribuídos em 22.190,70 ha; e 925 Unidades de Produção Agropecuária (UPA's) no Município de Tupi Paulista, distribuídos em $24.961,00$ ha (LUPA, 2008).

Ao se verificar o percentual de (UPA's) segundo a faixa de área, nota-se que $56,87 \%$ das unidades em Monte Castelo e $68,88 \%$ em Tupi Paulista apresentam áreas inferiores a 20 ha, o que evidencia a importância da agricultura familiar nas duas 
regiões, sendo as pequenas áreas, em sua grande maioria, trabalhadas diretamente pelos proprietários e pela família.

No Município de Monte Castelo, 402 (UPAs) tem suas áreas ocupadas com pastagem com uma área ocupada de (15.165,90 ha), seguido da cana-de-açúcar com (3.528,0 ha). Este município é produtor tradicional de urucum com uma área ocupada de 786,30 ha, mas também produz café, eucalipto, manga e seringueira (LUPA, 2008).

No município de Tupi Paulista, 857 (UPA's) tem suas áreas ocupadas com pastagem (16.983,30 ha), seguido de café com $3.672,60$ ha. Este municipio destaca-se na produção de uvas finas de mesa (cultivares itália, rubi, benitaka e outras) e de uvas rústicas de mesa (niagara), com uma área ocupada de 173,50 ha. O município produz também manga, seringueira e cana-de-açúcar (LUPA, 2008).

\section{Clima}

De acordo com o sistema de classificação de Köeppen, baseado nos valores médios de temperatura e precipitação, a região de Tupi Paulista e Monte Castelo, possui clima tipo Aw, ou seja, clima tropical úmido com estação chuvosa no verão e estação seca no inverno.

A precipitação média anual na região é da ordem de $1.300 \mathrm{~mm}$. O trimestre mais chuvoso corresponde aos meses de Dezembro, Janeiro e Fevereiro. O trimestre mais seco corresponde aos meses de Junho, Julho e Agosto.

\section{Uso do solo e cobertura vegetal}

Na região ocorrem remanescentes da vegetação nativa encontrados em pequenos maciços isolados das formações florestais constituídas de florestas. A vegetação original da região foi quase totalmente eliminada, restando poucos fragmentos mais preservados, mas que também vem sofrendo influência da ação do homem.

Na região ocorre a floresta estacional semidecidual, também conhecida como mata atlântica do interior. A fisionomia dessa classe está condicionada pela dupla estacionalidade climática: um verão com chuvas intensas, seguido de um inverno seco. Entre 20\% e 50\% das árvores perdem as folhas durante 0 periodo de seca (SMA, 2004).

\section{Caracterização dos estabelecimentos}

As 52 propriedades pesquisadas possuem em média 34 hectares, sendo que a menor área é de 3,29 hectares (ha) e a maior 150,00 ha. As propriedades que são menores que 50 ha totalizam 78,0\%. As Áreas de Preservação Permanente (APP) das propriedades pesquisadas possuem em média 1,34 ha, sendo que a menor área de APP é de 0,18 ha e a maior é de 16,07 ha. A grande maioria das propriedades $(63,46 \%)$ possui pequenas áreas de APP, menores do que 1,0 ha, portanto não demandou grande quantidade de trabalho e mão de obra para implantação da mata ciliar. Apenas 7,69\% das propriedades apresentam áreas de APP maiores do que 2,0 ha.

\section{Implantação do projeto de restauração} florestal

Quanto ao motivo que levou os produtores a implantar a mata ciliar na propriedade, $92,31 \%$ informaram que se deveu à notificação feita pela promotoria pública de Tupi Paulista, que exigiu dos proprietários rurais a restauração da APP de suas propriedades, situadas no Córrego do Galante, com o plantio de árvores nativas. Apenas $7,7 \%$ mencionaram que, além da obrigatoriedade, fizeram o reflorestamento com o objetivo de proteger o meio ambiente.

Todos os produtores citaram que para a implantação do projeto tiveram o apoio da CESP, que disponibilizou o projeto técnico, relatórios semestrais (quatro), as mudas de árvores nativas e a assistência técnica durante a implantação do projeto. Citaram também o apoio da Prefeitura de Monte Castelo que organizou a reunião com os interessados, transportou as mudas do Viveiro da CESP até os locais de plantio e atuou como um agente de mediação e interlocução entre a CESP e os produtores.

Com relação à mão de obra utilizada para a implantação do projeto $65,38 \%$ dos 
produtores afirmaram que contaram com mão de obra da própria familia; $5,77 \%$ utilizaram mão de obra de empregados da propriedade e $28,85 \%$ contratou mão de obra externa para a implantação do projeto.

No primeiro semestre de 2011, como parte da presente pesquisa, foi realizada uma avaliação técnica do reflorestamento das APPs de todas as 52 propriedades, situadas no Córrego do Galante, que participaram do Programa Fomento Florestal da CESP. A avaliação baseou-se em categorias que descrevem o grau de restauração em termos de composição e estrutura das áreas implantadas com reflorestamento, conforme já descrito na metodologia. Os resultados podem ser visualizados na Tabela 1.

Tabela 1. Qualidade do reflorestamento implantado nas APPs dos produtores pesquisados, na avaliação do pesquisador, em 2011.

\begin{tabular}{lcc}
\hline Qualidade do & $\mathbf{N}^{\circ}$ de & $\%$ de \\
\hline Plenamente restaurado & 39 & 75,00 \\
Quase totalmente restaurado & 5 & 9,62 \\
Parcialmente restaurado & 5 & 9,62 \\
Sem restauração & 3 & 5,77 \\
\hline Total & 52 & 100,00 \\
\hline
\end{tabular}

Fonte: Dados da pesquisa, 2011.

Entre os produtores, cuja área não estava plenamente restaurada, cinco não residem na propriedade e o reflorestamento foi conduzido por empregados, e em quatro casos mora somente uma pessoa da família na propriedade.

Os produtores cujas propriedades possuem APPs que não foram devidamente restauradas têm sido intimados pelo Ministério Público para a devida regularização. Portanto a adesão e execução do trabalho ocorreram em função da determinação do poder judiciário e não de um processo educativo e de convencimento dos produtores. Já a política pública de fomento florestal da CESP que permitiu viabilizar o reflorestamento tem adesão voluntária.

Foram levantadas também as maiores dificuldades que os produtores tiveram para implantação da mata ciliar (Tabela 2). Embora sejam bastante variadas, observa-se que o controle das plantas indesejáveis (especialmente gramineas) foi a principal dificuldade $(76,92 \%)$, pois outras respostas também estão parcialmente relacionadas com esta questão, como a falta de mão-de-obra, compra e aplicação de herbicida e coroamento das mudas.
Para o produtor de $n^{\circ} 1$ as maiores dificuldades foram para irrigar as mudas "tive que irrigar as mudas com balde, fazer o coroamento das mudas e tive prejuízo com lebres que cortavam as mudas".

Cinco produtores, apesar de terem nascido e vivido sempre no campo, tiveram dificuldades no manejo e condução do reflorestamento, porque nunca tinham plantado espécies arbóreas nativas e também porque a mão de obra da região não tem experiência com silvicultura.

O produtor de $n^{\circ} 43$ reclamou da falta de uma fiscalização mais rigorosa, pois se houvesse uma determinação firme com relação à necessidade de recompor a mata ciliar, o proprietário já teria buscado informações e a realizado. Também afirmou que aprova as medidas tomadas pela Promotoria Pública.

O entrevistado $n^{\circ} 24$ reclamou da falta de apoio dos técnicos da Casa da Agricultura do município, pois eles cobram para fazer os projetos técnicos de restauração florestal, então eles procuraram a CESP que tem o programa de fomento florestal que é gratuito.

Para a entrevistada $n^{\circ} 9$, os produtores do campo estão fazendo a sua 
Tabela 2. Dificuldades encontradas pelos produtores na implantação da mata ciliar.

\begin{tabular}{lcc}
\hline Dificuldades Encontradas & $N^{0}$ de & \% de Produtores \\
\hline Controle das gramíneas & 40 & 76,92 \\
Irrigação das mudas & 28 & 53,85 \\
Construção de cerca & 24 & 46,15 \\
Controle de formigas & 23 & 44,23 \\
Plantio das mudas & 7 & 13,46 \\
Compra e aplicação de & 6 & 11,53 \\
Custo da mão de obra & 6 & 11,53 \\
Falta de mão de obra & 5 & 9,61 \\
Compra de adubos & 4 & 7,69 \\
Coroamento das mudas & 2 & 3,84 \\
Falta de recursos financeiros & 2 & 3,84 \\
Ataque de lebre & 1 & 1,92 \\
Não teve dificuldades & 2 & 3,85 \\
\hline
\end{tabular}

Fonte: Dados da pesquisa, 2011.

parte, falta o moradores da cidade fazer o que Ihes cabe: "O córrego continua poluído, a cidade não está fazendo a sua parte, a mata ciliar está escondendo a poluição". A produtora refere-se ao fato de que o município de Tupi Paulista continua despejando o esgoto não tratado no Córrego do Galante.

Quanto aos aspectos positivos da implantação da mata ciliar (Tabela 3), na avaliação que os produtores rurais, o mais citado foi a proteção das margens do córrego, indicada por $65 \%$ dos entrevistados. Em seguida foi mencionado que o reflorestamento possibilitou "a volta dos pássaros" $(21 \%)$ e, mais genericamente, citou-se o mesmo que se tornou fonte de alimento e abrigo para a fauna $(21 \mathrm{t} \%)$. A melhoria da beleza cênica da paisagem também foi citada por $17 \%$ dos entrevistados.

Tabela 3. Pontos positivos da implantação da mata ciliar de acordo com os produtores.

\begin{tabular}{lcc}
\hline \multicolumn{1}{c}{ Pontos positivos } & N $^{0}$ de Produtores & \% de Produtores \\
\hline Proteção das margens & 34 & 65,38 \\
Volta dos pássaros & 11 & 21,15 \\
Fonte de alimento e abrigo para a fauna & 11 & 21,15 \\
Beleza cênica da APP & 9 & 17,30 \\
Adequação ambiental da propriedade & 6 & 11,53 \\
Melhoria da qualidade da água do córrego & 5 & 9,62 \\
Valorização da propriedade & 2 & 3,84 \\
Proteção da APP contra invasão de gado de & 1 & 1,92 \\
terceiros & 1 & 1,92 \\
Volta dos peixes ao córrego & & \\
\hline
\end{tabular}

Fonte: Dados da pesquisa, 2011. 
Os depoimentos, a seguir, mostram a satisfação dos produtores com as mudanças e em alguns casos a mudança de suas atitudes:

"Depois que a mata formou a APP ficou muito bonita, e é bom para proteger o Córrego"(Produtor n $\left.{ }^{\circ} 01\right)$.

"A mata é bom para proteção do córrego, valoriza a propriedade, a paisagem ficou bem melhor" (Produtor de $n^{\circ} 05$ ).

"A área de APP ficou bonita e dá gosto de ver as árvores crescidas e tomei gosto com plantio das mudas" (Produtor $n^{\circ} 8$ ).

"É bom para segurar a erosão, melhora o clima, valeu a pena o esforço para implantação da mata ciliar" (Produtor $n^{\circ} 40$ )

Para o Produtor $n^{\circ} 21$ a obrigatoriedade de todos recomporem a APP e principalmente cercar a área foi muito positiva, pois evitou a entrada de gado de estranhos em sua área: "antes era uma tristeza, minha área de APP estava sempre com gado de terceiros que invadiam $e$ utilizavam esta área para pastagem, cansei de chamar a polícia florestal para dar queixa".
Para o proprietário $n^{\circ} 12$ a recomposição da APP melhorou a qualidade da água do córrego: "melhorou o cheiro do córrego, acabou com os pernilongos, melhorou muito a qualidade da água, podia ter plantado as árvores antes".

Com relação aos aspectos negativos envolvidos na implantação da mata ciliar, 24 produtores $(46,15 \%)$ consideraram que não havia nenhum ponto a destacar. Os aspectos negativos foram citados por poucos entrevistados, ocorrendo certa dispersão das respostas, em função das dificuldades especificas de cada produtor. Os custos não cobertos para a recomposição da mata ciliar e a obrigatoriedade imposta pela promotoria foram os aspectos mais citados. Outros produtores apontaram a perda de área de pastagem, a falta de apoio técnico dos integrantes dos órgãos de assistência técnica estadual, as divergências técnicas a respeito da largura da APP (entre o técnico da CESP e o perito indicado pelo Ministério Público) e o fato do córrego continuar poluído (Tabela 4).

Tabela 4. Avaliação dos produtores sobre possiveis pontos negativos na implantação da mata ciliar.

\begin{tabular}{lcc}
\hline \multicolumn{1}{c}{ Pontos negativos } & $\mathbf{N}^{0}$ de Produtores & \% de Produtores \\
\hline Não tem pontos negativos & 24 & 46,15 \\
Obrigação imposta pela Promotoria & 5 & 9,61 \\
Não pagamento pela recomposição & 5 & 9,61 \\
Custo para recuperação da APP & 4 & 7,60 \\
Perda de área de pastagem & 4 & 7,60 \\
Discordância com a largura da APP & 3 & 5,76 \\
O córrego continua poluído & 3 & 5,76 \\
Falta de apoio dos órgãos de & 3 & 5,76 \\
$\begin{array}{l}\text { assistência técnica } \\
\text { Falta de um trabalho de informação }\end{array}$ & & 1,92 \\
dos órgãos ambientais & 1 & \\
\hline
\end{tabular}

Fonte: Dados da pesquisa, 2011.

Quatro entrevistados consideraram que o produtor deveria receber pela implantação da mata ciliar, pois teria perdido área de pastagem: "Diminuiu a minha área de pastagem, o governo deveria pagar a área que foi reflorestada" (Produtor $n^{\circ} 13$ ). Enquanto o Produtor n० 25 afirmou: "O Governo deveria ressarcir o produtor, pagar o valor da terra

onde foram plantadas as mudas".

O Produtor $n^{\circ} 14$ apontou a necessidade dos órgãos ambientais fazer um trabalho de educação ambiental prévio: "Antes de fazer a notificação, os órgãos ambientais deveriam fazer um trabalho de meio ambiente junto aos produtores".

Já o Produtor de $n^{\circ} 33$ destacou que o 
apoio público deveria acontecer em função dos benefícios amplos e duradouros que a recomposição das matas ciliares pode trazer: "falta de apoio do poder público, uma vez que os benefícios da mata ciliar são de toda a população".

No contexto atual da paisagem rural brasileira, caracterizado por processos históricos de fragmentação, e mais recentemente, pelo reconhecimento da importância das Áreas de Preservação Permanente em propriedades rurais, ganha importância a elaboração de modelos voltados à silvicultura e ao manejo de espécies nativas nessas áreas, pois o custo desta recomposição ainda é alto, em média $\mathrm{R} \$ 4.500,00 / \mathrm{ha}$, podendo chegar a R\$ 14.500,00/ha (IPEF, 2012).

O custo médio de implantação de 1,0 ha de reflorestamento cililar, com densidade de plantio de 1667 mudas/ha, é da ordem de $\mathrm{R} \$ 12.000,00$ para as áreas de propriedade da CESP. Nota-se, conforme discriminado na Tabela 5, que o custo do reflorestamento implantado por meio do Programa de Fomento Florestal corresponde a $23,4 \%$ do custo de implantação da CESP.

Tabela 5. Valor desembolsado pela CESP para restauração florestal de 69,57 ha na microbacia do Córrego do Galante, municípios de Tupi Paulista-SP e Monte Castelo-SP, 2012.

\begin{tabular}{lcccc}
\hline ITEM & UNIDADE & QUANTIDADE & R\$/UNIDADE & TOTAL (R\$) \\
\hline Engenheiro Agrônomo & Hora & 936 & 100,00 & $93.600,00$ \\
Transporte & Diária & 52 & 200,00 & $10.400,00$ \\
Refeição & Unidade & 52 & 35,00 & $1.820,00$ \\
Mudas nativas & Unidade & 115.973 & 0,75 & $86.979,75$ \\
Material de escritório & Unidade & 52 & 50,00 & $2.600,00$ \\
\hline TOTAL & & & & $195.399,75$ \\
TOTAL POR HECTARE & & & & $2.808,68$ \\
TOTAL POR PROJETO (52 Projetos) & & & $3.757,69$ \\
TOTAL POR MUDA PLANTADA (1667 mudas/ha) & & & 1,68 \\
\hline Fon Pados da pesquisa 2011 &
\end{tabular}

Fonte: Dados da pesquisa, 2011.

Para os proprietários rurais a parceria também gerou sensivel redução nos seus custos, pois receberam gratuitamente um pacote de serviços e produtos correspondente a $55 \%$ do valor total da implantação de um hectare de reflorestamento. Na Tabela 6 encontram-se os valores dos produtos e serviços fornecidos pela CESP, tendo como referência os preços praticados por profissionais que prestam este tipo de serviço na região.

Tabela 6. Valor médio dos serviços e produtos oferecidos pela CESP, por projeto, aos 52 participantes do Programa de Fomento Florestal desenvolvido na microbacia do córrego do Galante, Tupi Paulista-SP e Monte Castelo-SP, 2012.

\begin{tabular}{lcccc}
\hline ITEM & UNIDADE & QUANTIDADE & R\$/UNIDADE & TOTAL (R\$) \\
\hline Projeto técnico & Unidade & 1 & $2.000,00$ & $2.000,00$ \\
Vistoria semestral e relatório & Unidade & 4 & 600,00 & $2.400,00$ \\
Mudas florestais nativas & Unidade & 2230 & 1,00 & $2.230,00$ \\
\hline TOTAL & & & & $\mathbf{6 . 6 3 0 , 0 0}$ \\
\hline
\end{tabular}

Fonte: Dados da pesquisa, 2011. 


\section{CONCLUSÕES}

A principal caracteristica socioeconômica das propriedades do córrego do Galante reside no predomínio da agricultura familiar, aquela em que o envolvimento dos membros da família nas tarefas agrícolas é elevado. Contemporaneamente tem sido extremamente desafiadora para a agricultura familiar a necessidade de conjugar sustentabilidade econômica e ambiental. Os custos da implantação de projetos de reflorestamento para fins de restauração de APP, principalmente daqueles itens que necessariamente requerem o desembolso de capital (projeto, relatórios de acompanhamento, assistência técnica e aquisição de mudas), são praticamente inviáveis à grande maioria dos pequenos produtores rurais. Dessa forma, o programa de Fomento Florestal da CESP, que visa incentivar a instalação de áreas de mata ciliar e amenizar os impactos causados pela formação dos lagos para implantação das hidrelétricas, acabou por contribuir para viabilizar a recomposição da vegetação da APP das propriedades que haviam sido notificadas pelo Ministério Público Estadual. A formalização de parcerias interinstitucionais para este fim foi extremamente benéfica. A possibilidade de fazer a restauração florestal numa faixa contínua, onde diversos interessados eram contatados, para fins de elaboração dos projetos e acompanhamento técnico, numa única visita, proporcionou também a redução significativa dos custos individuais de cada projeto para a CESP.

A restauração das matas ciliares do córrego do Galante viabilizou a formação de um corredor ecológico, que uniu fragmentos florestais isolados, e dessa forma, potencialmente, facilitou o deslocamento da fauna e o fluxo gênico entre populações de espécies animais e vegetais.

A fixação de $\mathrm{CO}_{2}$ pelas matas ciliares restauradas também contribui para reduzir os efeitos de gases de efeito estufa que provocam o aquecimento global e mudanças climáticas. A recomposição ocorrida no
Córrego do Galante dará uma importante contribuição, ainda que pequena, neste sentido, tendo em vista servir de exemplo.

Os resultados alcançados podem fornecer aos poderes públicos e às organizações civis instrumentos que subsidiem a implantação de outros projetos de recuperação de matas ciliares. $\mathrm{O}$ apelo da conservação do córrego do Galante como fonte de água e recurso para a agricultura e pecuária deveria ser aproveitado em projetos futuros, como motivação e simbologia para outras ações de recuperação do meio ambiente, envolvendo parcelas mais amplas da população dos municípios e da região.

Cabe destacar que a Promotoria Pública de Tupi Paulista foi o agente indutor do processo, ao exercer pressão sobre os proprietários rurais para estes realizassem a restauração florestal das APPs nos seus imóveis. A exigência dos relatórios semestrais proporcionou condições para que, nos casos em que as operações previstas no projeto não estivessem sendo realizadas conforme previsto no cronograma de implantação, medidas corretivas fossem tomadas. Esse acompanhamento da Promotoria Pública foi decisivo para que os projetos fossem implantados.

Além da atitude fiscalizadora dos órgãos ambientais, seria importante um trabalho educativo, de extensão ambiental, para conscientização e capacitação dos produtores rurais para lidar com recuperação de áreas degradadas. A realização de um trabalho contínuo de educação ambiental, tendo como integrantes estudantes, professores, comunidade e órgãos ambientais do Estado, contribuiria para uma maior conscientização de questões referentes à recuperação das matas ciliares e ao envolvimento dos produtores rurais.

A instituição de regras para o PSA Pagamento por Serviços Ambientais pode também ser um instrumento econômico para a restauração de Áreas de Preservação Permanente e para melhoria das condições de vida de pequenos produtores rurais. Os proprietários seriam os provedores de serviços ambientais e receberiam por isso, e 
os recursos poderiam vir do Fundo Estadual de Recursos Hídricos (Fehidro).

O uso do Sistema Agroflorestal (SAF) para recuperação de APPs também pode ser uma ferramenta para os produtores familiares, pois, além do componente ambiental, ter-se-ia um estímulo econômico para recuperação de áreas degradadas no meio rural. A Resolução SMA-44, de 30-06-2008, que define critérios e procedimentos para a implantação de Sistemas Agroflorestais em Área de Preservação Permanente na pequena propriedade ou posse rural familiar é um instrumento legal que pode ser utilizado.

Consideramos que o projeto beneficiou os dois principais parceiros envolvidos. A CESP ganhou com a conservação dos recursos hídricos, matéria prima para a produção de energia hidrelétrica, e exercitou sua responsabilidade ambiental nas áreas de influência de seus empreendimentos. Para os proprietários os ganhos foram a conformidade com a legislação ambiental, a beleza cênica e a valorização de suas propriedades e seus produtos, em uma sociedade cada vez mais exigente quanto à sustentabilidade ambiental.

\section{REFERÊNCIAS}

CESP. Recuperação de áreas degradadas. 2. Ed. São Paulo: CESP, 1992, 12 p. (Série Pesquisa e Desenvolvimento, 059)

FUNDAÇÃO SEADE. Perfil municipal. São Paulo: SEADE, 2009. Disponível em: http://www.seade.gov.br/. Acesso em: 14 abr. 2012.

IPEF. Revista IPEF Notícias. Janeiro/Fevereiro, ano 38, n. 213, p. 5, 2012.

KAGEYAMA, P. Y; OLIVEIRA, R. E.; MORAES, L. F. D.; ENGEL, V. L.; GANDARA, F. B. Restauração ecológica de ecossistemas naturais. Piracicaba: Fundação de Estudos e Pesquisas Agrícolas Florestais. 2003.340p.
SMA - SECRETARIA DE MEIO AMBIENTE. Projeto de recuperação de matas ciliares: nota conceitual. São Paulo: SMA, 2004. 86 p. (Mimeo)

SMA - SECRETARIA DE MEIO AMBIENTE. Cadernos da Mata ciliar, Monitoramento de áreas em recuperação n ${ }^{\circ}$ 4. São Paulo: SMA, 2011.63p.

LUPA-SÃO PAULO. Secretária de Agricultura e Abastecimento. Coordenadoria de Assistência Técnica Integral. Instituto de Economia Agrícola. Levantamento censitário de unidades de produção agrícola do Estado de São Paulo 2007/2008. São Paulo: SAA/CATI/IEA, 2008. D i s p o n i v e I e $\mathrm{m}$ : http://www.cati.sp.gov.br/projetolupa. Acesso em: 15 abr. 2012. 